\title{
Three dimensional echocardiography: a valuable tool to assess left atrial function in non-compaction cardiomyopathy!
}

\author{
Leo H. B. Baur
}

Received: 28 August 2007/ Accepted: 28 August 2007 / Published online: 28 September 2007

(C) Springer Science+Business Media B.V. 2007

Non-compaction of the ventricular myocardium is the result of an arrest in myocardial morphogenesis. It is characterised by by prominent and excessive trabeculations in the left ventricular wall, with deep intertrabecular spaces perfused from the ventricular cavity $[1,2]$. Sometimes, it is associated with other congenital heart defects such as severe obstruction of right or left ventricular outflow tracts and anomalous origin of the left coronary artery from the pulmonary trunk [3]. The crucial diagnostic characteristic of noncompaction is the 2-layered myocardial wall consisting of a thin epicardial compacted zone and extremely thickened endocardial noncompacted zone. Usually a ratio of noncompacted/compacted zone more than two is diagnostic for ventricular noncompaction. Non compaction cardiomyopathy frequently is associated with systolic and diastolic left ventricular dysfunction, endocardial clot formation and ventricular arrhythmias. The study of Nemes et al in this issue of the International Journal of Cardiac Imaging shows, that left atrial systolic function is increased in patients with non-compaction cardiomyopathy [4]. This is probably due to impaired diastolic

L. H. B. Baur ( $\square)$

Department of Cardiology, Atrium Medical Centre

Parkstad, Henri Dunantstreet 5, 6401CX Heerlen,

The Netherlands

e-mail: 1.baur@atriummc.nl filling of the left ventricle. In this study, assessment of left atrial force was done by real time 3D echocardiography. Three dimensional echocardiography has proven to be a reliable method for assessment of left atrial ejection fraction [5]. It can therefore be used for accurate determination of left atrial function in several disease states. Unfortunately, the authors did not show us the improved accuracy of three dimensional echocardiography above two dimensional echocardiography in measurement of left atrial force. However, the results of their work should encourage clinicians and scientists to evaluate left atrial force in more disease states with three dimensional echocardiography. Additionally, the described method can be used to evaluate the effect of therapy in patients with diastolic abnormalities, restrictive filling and in patients with atrial fibrillation. If left atrial force and function measurement are able to be related to the onset of atrial rhythm disturbances, it could then be possible to prevent atrial fibrillation by early treatment of atrial dysfunction. The underlying study already shows, that in patients with noncompaction cardiomyopathy, left atrial function is increased compared to normal controls. This to compensate for the decreased left ventricular function. Further studies are needed to evaluate the clinical role of left atrial function parameters and to look for left atrial function in relation to therapy. Three dimensional echocardiography can be a valuable tool for this. 


\section{References}

1. Süheyla Özkutlu, Canan Ayabakan, Alpay Çeliker, Huda Elshershari (2002) Noncompaction of ventricular myocardium: a study of twelve patients. J Am Soc Echocardiogr 15:1523-1528

2. Buonanno C, Variola A, Dander B, Gabaldo S, Marafioti V (2000) Isolated noncompaction of the myocardium: an exceedingly rare cardiomyopathy: a case report. Ital Heart J 1:301-305

3. Kohl T, Villegas M, Silverman N (1995) Isolated noncompaction of ventricular myocardium-detection during fetal life. Cardiol Young 5:187-189
4. Nemes A, Anwar AM, Caliskan K, Soliman OI, van Dalen B, Geleijnse ML, Ten Cate F (2007) Evaluation of left atrial systolic function in non-compaction cardiomyopathy bt realtime three dimensional echocardiography. Int J Cardiac Imaging doi: 10.1007/s10554-007-9261-5

5. Anwar AM, Soliman OI, Geleijnse ML, Michels M, Vletter WB, Nemes A et al (in press) Assessment of left atrial ejection force in hypertrophic cardiomyopathy using realtime three dimensional echocardiography. J Am Soc Echocardiogr 